BLS 32, No 1 2006. DOI: http://dx.doi.org/10.3765/bls.v32i1.3442 (published by the Berkeley Linguistics Society and the Linguistic Society of America)

\title{
Constrained Flexibility in the Extension of Novel Causative Verbs
}

\author{
ANN BUNGER and JEFFREY LIDZ \\ Northwestern University and University of Maryland
}

\section{Introduction}

Whenever we learn a novel word, whatever its grammatical category, what we are learning is a label for a whole category of things in the world. The word $d o g$, for example, refers not to an individual dog, but to the whole set of dog-like things in the world. Likewise, the word jump refers not to a single instance of jumping, but to an entire category of jumping events. A large literature has grown up around the kinds of categories that children assign to novel nouns, asking, for example, whether a novel count noun refers to a particular individual, to a basic level category, or to a superordinate category (e.g. Markman 1993, Waxman 1990). The corresponding questions have not been asked, however, about novel verbs, i.e. what categories of events a novel verb can be extended to include.

It is well established that there are systematic regularities in the mapping between verb meaning and verb syntax, such that verbs that refer to similar event types, i.e. verbs that have similar meanings, can occur in similar sentence structures (e.g. Carter 1976, Gruber 1965, Jackendoff 1990, Levin 1993). We know, for example, that only verbs that label a change of state can occur in the so-called causative-inchoative alternation, illustrated by the sentences in (1). Note that the verb bounce can be used both in a transitive frame (1a) and in an unaccusative intransitive frame (1b), but that hit cannot (2). The discrepancy between these two patterns of use is due to the fact that only bounce labels some change of state undergone by the ball; on the contrary, in (2a) it's Sammy that does the hitting, not the ball.

(1) a. Michael Jordon bounced the ball.

b. The ball bounced.

(2) a. Sammy Sosa hit the ball.

b. *The ball hit.

Theorists and researchers in a range of disciplines have suggested that very early event representations may encode features that map directly onto linguistic 


\section{Ann Bunger and Jeffrey Lidz}

structures, perhaps providing cues for language learning (e.g. Gordon 2004, Mandler 1992). And from studies investigating the syntactic bootstrapping hypothesis, we know that young children can indeed tap into their knowledge of the mapping between verb syntax and verb semantics and use cues from the syntactic structures a novel verb occurs in to constrain their hypotheses about its meaning (e.g. Bunger and Lidz 2004, 2006; Fisher 1996; Gleitman 1990; Landau and Gleitman 1985; Lidz et al. 2003; Naigles 1990). Naigles (1990) demonstrates, for example, that two-year-old children can use cues from syntax to help them figure out which of two simultaneous events is being labeled by a novel verb. And in an earlier paper, we took these findings a step further to demonstrate that twoyear-olds can also use cues from syntax to figure out which subpart of a single complex event is being labeled by a novel verb (Bunger and Lidz 2004).

The complex events that we have been studying are causative events, those in which some agent performs an action that causes some change of state in another entity. Imagine, for example, an event in which a girl makes a ball bounce by hitting it repeatedly with her hand, i.e. she dribbles the ball. Our work shows that children of this age, like adults, represent events of direct causation as decomposable into several distinct subparts, as depicted in (3):

$$
\begin{gathered}
\text { [[girl hits ball] CAUSE [ball bounces] }] \\
\text { MEANS }
\end{gathered}
$$

First, there's the means subevent, which corresponds to whatever action the causative agent is performing that brings about a change of state in the other relevant entity; in this case, it is the girl's hitting of the ball. Then there's the result subevent, which corresponds to the entity's change of state; in this case, it is the ball's bouncing. And then there's also the notion of causation, the relation that links the other two subevents to each other; in this case, it represents our understanding that the ball's bouncing is a direct result of the girl's hitting of the ball.

The linguistic evidence for these subparts comes from the fact that single verbs can refer to the individual subparts as well as to various combinations of the subparts.
a. The girl hit the ball.
MEANS
b. The ball bounced.
RESULT
c. The girl dribbled the ball.
CAUSATIVE EVENT

So, the verb hit used in a transitive frame (4a) labels only the means subevent, and the verb bounce used in an unaccusative intransitive frame (4b) labels only the result subevent, but the verb dribble used in a transitive frame (4c) encodes the entire causative event, both the result and the idea that that result has been caused by the girl hitting the ball in a characteristic way.

One thing that we know is true cross-linguistically of verbs labeling causative events is that languages don't have verbs that encode subparts of the causative 


\section{Flexible Extension of Novel Causative Verbs}

that aren't constituents (e.g. Rappaport Hovav and Levin 1998). So, for example, single verbs can label any of these individual subevents of the causative, or they can label the entire event, but languages don't have verbs that encode, for example, something like a means subevent and a result subevent that aren't causally related.

The broad goal of the research described here was to examine the constraints that guide language learners in their acquisition of novel verbs. To address this issue, we sought to gain a more precise idea of the different ways that two-yearolds are willing to use single verbs to encode the subparts of a causative event by investigating two more specific questions. First, we wanted to find out how children of this age are willing to package information about causative events into verbs, i.e. whether they would be willing to accept any combinations of the subparts of a complex causative as the meaning of a single verb, or whether they, like adults, would be constrained by something like the constituency constraint.

Second, we wanted to find out how flexible the world-to-word mapping is for verbs labeling causative events, i.e. how specific children are about the event features they're encoding when they're acquiring a novel verb. So, for example, when they see a girl dribbling a ball and hear it described with a novel verb like pimming, we want to know whether pimming has to mean something very specific like 'cause to bounce by hitting', or whether the semantic identity of the means and result subevents might be underspecified, with alternate meanings like 'cause to bounce by performing some unspecified action' or even 'cause to move in some unspecified way by performing some unspecified action'.

To investigate these questions, we designed two experiments using the preferential looking paradigm (e.g. Golinkoff et al. 1987, Spelke 1979). Experiment 1 explores children's flexibility in encoding the semantic content of the means subpart of a causative, and Experiment 2 explores their flexibility in encoding the semantic content of the result subpart.

\section{Experiment 1: Means Subevent \\ 1.1. Design}

The participants in Experiment 1 consisted of 24 two-year-olds (six boys and six girls in each experimental condition) ranging in age from 22;7 (months; days) to 26;1 (mean 23;29). All were being raised in English-speaking homes.

The stimuli consisted of short live-action videos depicting human actors interacting with inanimate objects. Each trial consisted of two phases: familiarization and test. During the familiarization phase, participants saw a video of some causative event in which an actor caused a change of state in an inanimate object, e.g. a girl making a ball bounce by hitting it repeatedly with a tennis racquet. Each showing of the event was accompanied by a digitally synchronized auditory event description that included a novel verb. This event-description pairing was shown four times (for six seconds each time) and on both sides of a large projection screen: first once on each of the left and right sides of the screen, and then twice on both sides simultaneously. 


\section{Ann Bunger and Jeffrey Lidz}

There were two experimental conditions differing between subjects, which were distinguished by the syntactic frame in which the novel word was presented during familiarization. Participants in the unaccusative condition heard the novel verb used in an unaccusative intransitive sentence like The ball is pimming, and participants in the transitive condition heard the novel verb used in a transitive sentence like The girl is pimming the ball.

Between the third and fourth presentations of the causative event, participants saw a six-second contrast event in which the actor was engaged in a noncausative activity involving the inanimate object. In the case of the causative event involving the girl and the ball, for example, the contrast event consisted of the girl holding the ball in her hands and moving it back and forth in an arc across the screen. The contrast event was accompanied by an auditory event description that also incorporated the novel verb, but that made it clear that the event encoded by the novel verb was not happening.

Each participant saw four different familiarization sequences, each with a different causative event described using a different novel verb. A complete list of the causative events and their accompanying contrast events is given in (5). Novel verbs were repeated twice during each familiarization sequence, for a total of ten presentations each.

Familiarization and contrast events

\begin{tabular}{|c|c|c|}
\hline Novel verb & Causative event & Contrast event \\
\hline grek & $\begin{array}{l}\text { girl turns crank attached to } \\
\text { light; light bulb turns on }\end{array}$ & girl puts light on her head \\
\hline blick & $\begin{array}{l}\text { boy pumps bike pump at- } \\
\text { tached to garden flower; } \\
\text { flower spins }\end{array}$ & $\begin{array}{l}\text { boy waves flower back and } \\
\text { forth }\end{array}$ \\
\hline pim & $\begin{array}{l}\text { girl hits ball with tennis } \\
\text { racquet; ball bounces }\end{array}$ & girl swings ball back and forth \\
\hline lorp & $\begin{array}{l}\text { boy hits ring tower with stick; } \\
\text { tower rocks back and forth }\end{array}$ & boy turns tower over and over \\
\hline
\end{tabular}

In the test phase of each trial, participants were shown two new events, presented simultaneously on opposite sides of the screen, and the auditory stimulus directed them to find the action labeled by the novel verb presented during familiarization. Both of the test events involved the person and objects presented during familiarization, but they differed in which of the subparts of the familiarized causative event were repeated. One of the test events was a causative 


\section{Flexible Extension of Novel Causative Verbs}

event that differed from the familiarization event in the means of causation (New Means test event) and the other was an event in which no causation occurred, but both the means and the result presented during familiarization were repeated (No Cause test event). In both test events, then, the result subevent was the same as that presented during familiarization, but in the New Means test event, the means by which that result was brought about was changed and in the No Cause test event, the means and the result subevents were both repeated, but they were no longer causally related. A schematic depiction of a representative trial, including specific examples of test events, is given in (6).

(6) Representative trial: Experiment 1, unaccusative condition

\begin{tabular}{|c|c|c|c|}
\hline Phase & $\begin{array}{l}\text { Left side of } \\
\text { screen }\end{array}$ & $\begin{array}{l}\text { Right side of } \\
\text { screen }\end{array}$ & Audio track \\
\hline \multirow[t]{3}{*}{ Familiarization } & $\begin{array}{l}\text { girl bounces } \\
\text { ball by hitting it } \\
\text { with a racquet }\end{array}$ & black screen & $\begin{array}{l}\text { Look! The ball is } \\
\text { pimming. Do you see } \\
\text { the ball pimming? }\end{array}$ \\
\hline & black screen & $\begin{array}{l}\text { girl bounces } \\
\text { ball by hitting it } \\
\text { with a racquet }\end{array}$ & $\begin{array}{l}\text { Wow! The ball is } \\
\text { pimming. Do you see } \\
\text { the ball pimming? }\end{array}$ \\
\hline & $\begin{array}{l}\text { girl bounces } \\
\text { ball by hitting it } \\
\text { with a racquet }\end{array}$ & $\begin{array}{l}\text { girl bounces } \\
\text { ball by hitting it } \\
\text { with a racquet }\end{array}$ & $\begin{array}{l}\text { Yay! The ball is } \\
\text { pimming. Do you see } \\
\text { the ball pimming? }\end{array}$ \\
\hline Contrast & \multicolumn{2}{|c|}{$\begin{array}{l}\text { (centered) } \\
\text { girl waves ball from side to side }\end{array}$} & $\begin{array}{l}\text { Oh no! Now the ball is } \\
\text { not pimming. The ball } \\
\text { is not pimming. }\end{array}$ \\
\hline Familiarization & $\begin{array}{l}\text { girl bounces } \\
\text { ball by hitting } \\
\text { it with a racquet }\end{array}$ & $\begin{array}{l}\text { girl bounces } \\
\text { ball by hitting it } \\
\text { with a racquet }\end{array}$ & $\begin{array}{l}\text { Yay! Now the ball is } \\
\text { pimming. Do you see } \\
\text { the ball pimming? }\end{array}$ \\
\hline Test & $\begin{array}{l}\text { New Means } \\
\text { girl bounces ball } \\
\text { by hitting it with } \\
\text { her hand }\end{array}$ & $\begin{array}{c}\text { No Cause } \\
\text { girl waves } \\
\text { racquet but does } \\
\text { not hit ball; ball } \\
\text { bounces }\end{array}$ & $\begin{array}{l}\text { Oh look, they're } \\
\text { different. Do you see } \\
\text { pimming? Do you see } \\
\text { pimming? Where's } \\
\text { pimming now? }\end{array}$ \\
\hline
\end{tabular}




\section{Ann Bunger and Jeffrey Lidz}

Stimulus videos were presented on a projection screen suspended from the ceiling of a dark room. Participants were tested individually, seated approximately six feet from the screen, and were free during the experiment to sample the contents of the entire screen. Attention to the stimuli was recorded using a digital video camera situated just below the screen, and these recordings were coded for direction of the participant's visual fixation during the test phase. An ANOVA was performed to test for differences in mean visual fixation to the New Means and No Cause test events across experimental conditions.

\subsection{Results and Discussion}

In essence, the goal of this experiment is to find out whether two-year-old children would be more willing to extend the meaning of the novel verb presented during familiarization to refer to an event that is of the same event type as the familiarization event (i.e. a causative event), but that differs in the semantic content of the means subevent, or to an event that is of a completely different event type than the familiarization event (i.e. not a causative event), but that matches the familiarization event in perceptually salient ways. The relevant question to ask when examining these data, then, is which of the test events participants were willing to accept as an extension of the meaning of the novel verb presented during familiarization. Previous studies using the preferential looking paradigm have shown that children tend to look longer at a scene that matches the speech stimulus. In this experiment, then, we expect participants to look longer at the test event that they were willing to label with the novel verb presented during familiarization.

Previous work in syntactic bootstrapping has demonstrated, furthermore, that the meaning that two-year-old children assign to a novel verb is heavily influenced by the syntactic frame in which that novel verb is presented. Given this effect, we expect to find differences in patterns of looking across conditions that reflect the mapping between verb meaning and verb syntax.

The figure in (7) depicts the mean proportion of looks by participants in each condition toward the causative New Means test event. Data are presented from a two-second salience period at the beginning of the test phase and from a twosecond window around the first mention of the novel verb in the test audio. During the salience period, participants have not yet heard the novel verb repeated, and so looking patterns during this time just reflect baseline preferences for the two test events. Looking patterns around the first mention of the novel verb, on the other hand, should reflect the interpretation that participants have assigned to it. 


\section{Flexible Extension of Novel Causative Verbs}

(7)

Mean visual fixation at test: Experiment 1

*In the transitive condition, attention to test events was significantly different during salience vs. at the first mention of the novel word in the test audio.

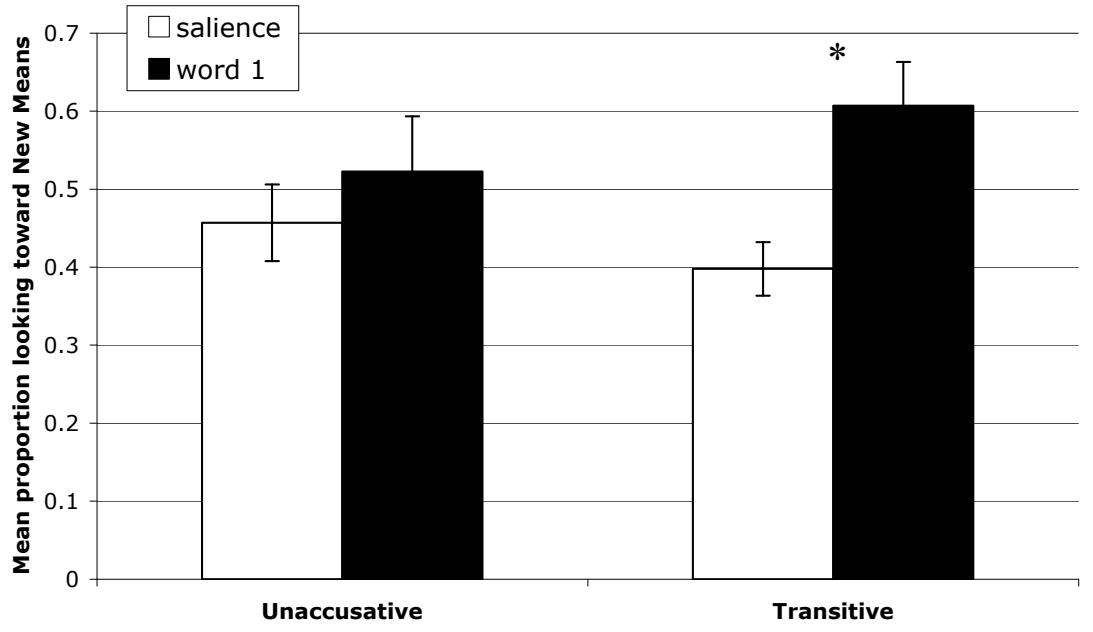

When asked to find the test event that could be labeled by the novel verb presented during familiarization, participants in the unaccusative condition showed no significant preference for either test event $(p=0.45)$. This result is not surprising if we consider that in English, the verb in an unaccusative intransitive frame invariably labels the result of a causative event: compare the novel verb pimming (8a) to the verbs in (8b), each of which we understand as a description of some change of state being undergone by the ball.

a. The ball is pimming.

b. The ball is bouncing/spinning/rolling.

In this experiment, the result subevent presented during familiarization was present in both of the test events, and so both of the test events should have provided an adequate match for the novel unaccusative verb. We can take the lack of preference in this condition, then, as a sign that these participants interpreted the novel verb presented in an unaccusative intransitive frame as a label for just the result of a causative event.

Participants in the transitive condition, on the other hand, showed a significant increase in their preference for the causative New Means test event when asked to find the referent of the novel verb $(p=0.004)$. Note that unlike the unaccusative frame, a transitive frame does not provide an unambiguous cue for the meaning of a novel verb (9a): the verb in a transitive frame can label either just the means subevent of a causative, like hit (9b), or it can label an entire causative event, like dribble (9c). 


\section{Ann Bunger and Jeffrey Lidz}
a. The girl is pimming the ball.
b. The girl is hitting the ball.
c. The girl is dribbling the ball.

The preference that participants in this experiment show for the New Means test event, then, can be taken as further evidence that children of this age are biased to interpret verbs in a transitive frame as causatives (Lidz et al. 2003). Note, however, that participants chose to extend the meaning of the novel verb to include causative test events that differed from the familiarization events in the means by which that causation was brought about. This suggests that children of this age permit some flexibility in the semantic content they assign to the means subevent of a causative representation.

\section{Experiment 2: Result Subevent}

In Experiment 1, we observed that two-year-olds grouped two of the subparts of a causative representation together, i.e. the cause and result subparts, when extending the meaning of a novel transitive verb, and that they allowed for flexibility in the identity of the means subevent. What we didn't know was whether this was the only possibility for grouping the subparts, or whether if they were given the opportunity, children of this age would also be willing to group the means and cause subparts together without identifying a specific result. If so, this might suggest that what they've learned about these verbs is that they label causative events of some type, with no commitment to the identity of the means or the result subevents. The goal of our second experiment was to explore this possibility by investigating two-year-olds' flexibility in encoding the semantic content of the result subpart of a complex causative.

\subsection{Design}

A total of 24 two-year-olds (six boys and six girls in each experimental condition) ranging in age from 22;12 to 25;25 (mean 23;28) participated in Experiment 2. All were being raised in English-speaking homes, and none had participated in Experiment 1.

This experiment also employed the preferential looking paradigm. Participants were presented with exactly the same causative familiarization events accompanied by novel verbs that were used in Experiment 1, and at test they were asked to determine which of two new events could also be labeled by the novel verb. Experiment 2 differed from Experiment 1 in two ways: first, in the syntactic frames used to present novel verbs during familiarization, and second, in the combinations of subparts of the familiarized causative event that were repeated in the test events.

In this experiment, participants were assigned either to an unergative condition in which they heard the novel verb used in an unergative intransitive sentence like The girl is pimming or to a transitive condition in which they heard the novel verb used in a transitive sentence like The girl is pimming the ball. 


\section{Flexible Extension of Novel Causative Verbs}

Recall that in Experiment 1, both test events included the same result subevent presented in the familiarized causative, but they varied in whether that change of state was caused or not. In Experiment 2, both test events include the familiarized means activity, but they vary in whether that activity is still a means of causation. Participants were given the option of extending the novel verb to refer either to a causative event that differed from the familiarization event only in the change of state undergone by the object (New Result test event) or to the same No Cause test events that were presented in Experiment 1. Specific examples of the test events that would follow the causative pimming event detailed in (6) are presented in (10).

Test events: Experiment 2

\begin{tabular}{l|c|c|c}
\hline \hline Phase & $\begin{array}{c}\text { Left side of } \\
\text { screen }\end{array}$ & $\begin{array}{c}\text { Right side of } \\
\text { screen }\end{array}$ & Audio track \\
\hline Test & $\begin{array}{c}\text { New Result } \\
\text { girl deflates } \\
\text { ball by hitting } \\
\text { it with the } \\
\text { racquet }\end{array}$ & $\begin{array}{c}\text { No Cause } \\
\text { girl waves } \\
\text { not hit ball; ball } \\
\text { bounces }\end{array}$ & $\begin{array}{c}\text { Oh look, they're different. } \\
\text { Do you see pimming? Do } \\
\text { you see pimming? Where's } \\
\text { pimming now? }\end{array}$ \\
\hline \hline
\end{tabular}

As in Experiment 1, attention to the stimuli was recorded using a digital video camera, and these recordings were coded for direction of the participant's visual fixation during the test phase. An ANOVA was performed to test for differences in mean visual fixation to the New Result and No Cause test events across experimental conditions.

\subsection{Results and Discussion}

Complementary to that of Experiment 1, the goal of Experiment 2 was to find out whether two-year-old children would be more willing to extend the novel verb presented during familiarization to refer to an event that is of the same (causative) event type as the familiarization event, but that differs in the semantic content of the result subevent, or to an event that is of a completely different event type than the familiarization event (i.e. it's not a causative event), but that matches it in easily observable ways. Again, our general prediction is that participants will look longer at the test event that they are willing to label with the novel verb presented during familiarization. 


\section{Ann Bunger and Jeffrey Lidz}

(11) Mean visual fixation at test: Experiment 2

*In both conditions, attention to test events was significantly different during salience vs. at the first mention of the novel word in the test audio.

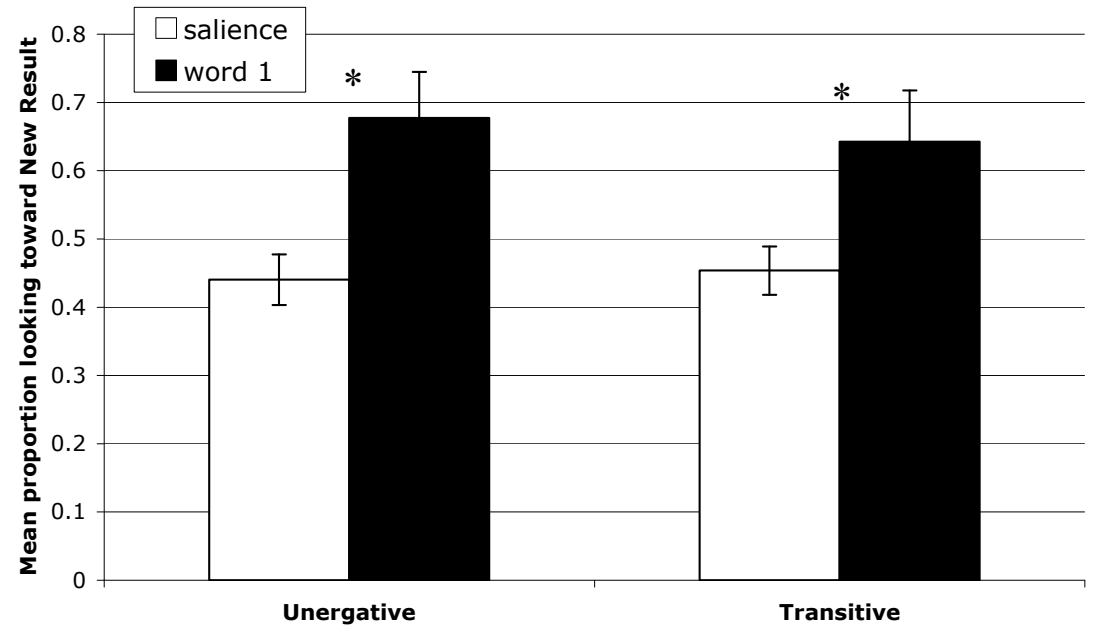

The graph in (11) depicts the mean proportion of looks toward the causative New Result test event during a two-second salience period and in the two seconds around the first mention of the novel word in the test audio. The results show that when asked to find the test event that could be labeled by the novel verb presented during familiarization, participants in both the unergative $(p=0.005)$ and the transitive $(p=0.03)$ conditions showed a significant preference for the causative test event. This suggests that participants in both of these conditions interpreted the novel verb as a label not for a specific subevent, but rather as a label for the entire causative event. Recall, moreover, that these two-year-olds chose to extend the meaning of the novel verb to include causative test events that differ from the familiarization events in the change of state induced by the causative agent. This suggests that children of this age permit some flexibility in the semantic content they assign to the result subevent of a causative representation.

\section{Conclusions}

Taken together, the results of these two experiments give us some initial insight into the categories of events that a novel verb can be extended to include. This study confirms, first, that two-year-olds can use cues from syntax to identify and label the subparts of an internally complex causative event. In Experiment 1, for example, when participants heard the novel verb in an unaccusative frame, they understood it to refer to just the result subevent of the complex causative, but when they heard it in a transitive frame, they understood it to refer to the entire causative event.

Our results suggest, furthermore, that two-year-old children are limited in the way that they can map verb meanings onto structural representations of events, 


\section{Flexible Extension of Novel Causative Verbs}

such that verbs can only encode subparts of the representation that correspond to possible structural representations. Recall that across both experiments we never saw an overall preference for the No Cause test events, in which the means and result subevents were repeated but were not causally related. This demonstrates that these participants were unwilling to extend the novel verb to refer to an event that includes subparts of the familiarization event that are not constituents.

Interestingly, however, we find that as long as that structural constraint is satisfied, two-year-olds can be flexible in the specificity of the semantic content they assign to their representation of the causative. What we've done in these experiments essentially is to ask these two-year-olds to extend a novel verb to refer to an event that conflicts with the familiarized causative in one of two ways. They have the choice of extending the verb to refer either (i) to an event that is still of the same conceptual type as the one presented during familiarization, i.e. one that is still a causative, but that differs in the identity of the means or result subevents, or (ii) to an event that is perceptually similar to the familiarized event, i.e. one that includes the same subevents, but that is of a different event type. What we have found is that they are willing to loosen their commitment to the semantics of an event, i.e. in what they will permit as the means or the result subevent of a causative, but not to the kind of event representation they have assigned to the verb, i.e. they still represent the meaning as causative. This kind of flexibility would be an extremely powerful tool for word learning, allowing children to refine their hypotheses about the meanings of words they are acquiring as they encounter new information about them in the world.

\section{References}

Bunger, Ann, and Jeffrey Lidz. 2004. Syntactic Bootstrapping and the Internal Structure of Causative Events. Proceedings of the Annual Boston University Conference on Language Development 28:74-85.

Bunger, Ann, and Jeffrey Lidz. 2006. Constrained Flexibility in the Acquisition of Causative Verbs. Proceedings of the Annual Boston University Conference on Language Development 30:60-71.

Carter, Richard. 1976. Some Constraints on Possible Words. Semantikos 1:27-66.

Fisher, Cynthia. 1996. Structural Limits on Verb Mapping: The Role of Analogy in Children's Interpretations of Sentences. Cognitive Psychology 31:41-81.

Gleitman, Lila. 1990. The Structural Sources of Verb Meanings. Language Acquisition 1:3-55.

Golinkoff, Roberta M., Kathryn Hirsh-Pasek, Kathleen M. Cauley, and Laura Gordon. 1987. The Eyes Have It: Lexical and Syntactic Comprehension in a New Paradigm. Journal of Child Language 14:23-45.

Gordon, Peter. 2004. The Origin of Argument Structure in Infant Event Representations. Proceedings of the Annual Boston University Conference on Language Development 28:189-198. 
Ann Bunger and Jeffrey Lidz

Gruber, Jeffrey. 1965. Studies in Lexical Relations. Ph.D. dissertation, MIT. Jackendoff, Ray. 1990. Semantic Structures. Cambridge, MA: MIT Press.

Landau, Barbara, and Lila R. Gleitman. 1985. Language and Experience: Evidence from the Blind Child. Cambridge, MA: Harvard UP.

Levin, Beth. 1993. English Verb Classes and Alternations: A Preliminary Investigation. Chicago: University of Chicago.

Lidz, Jeffrey, Henry Gleitman, and Lila Gleitman. 2003. Understanding How Input Matters: Verb-Learning and the Footprint of Universal Grammar. Cognition 87:151-178.

Mandler, Jean M. 1992. How to Build a Baby: II. Conceptual Primitives. Psychological Review 99:587-604.

Markman, Ellen M. 1993. Constraints Children Place on Word Meanings. In P. Bloom, ed., Language Acquisition: Core Readings, 154-173. Cambridge, MA: MIT Press.

Naigles, Letitia. 1990. Children Use Syntax to Learn Verb Meanings. Journal of Child Language 17:357-374.

Rappaport Hovav, Malka, and Beth Levin. 1998. Building Verb Meanings. In M. Butt and W. Geuder, eds., The Projection of Arguments: Lexical and Compositional Factors, 97-134. Stanford: CSLI.

Spelke, Elizabeth S. 1979. Perceiving Bimodally Specified Events in Infancy. Developmental Psychology 15:626-636.

Waxman, Sandra R. 1990. Linguistic Biases and the Establishment of Conceptual Hierarchies: Evidence from Preschool Children. Cognitive Development 5:123-150.

Ann Bunger ${ }^{1}$

Department of Linguistics

2016 Sheridan Road

Northwestern University

Evanston, IL 60208-0854

abunger@northwestern.edu
Jeffrey Lidz

Department of Linguistics

1401 Marie Mount Hall

University of Maryland

College Park, MD 20742-7505

jlidz@umd.edu

\footnotetext{
${ }^{1}$ This research was supported in part by National Institutes of Health grant R03-DC006829 to J. Lidz and by a Northwestern University Graduate Research Grant to A. Bunger. The authors wish to express their gratitude to the children and parents who participated in these experiments and to receptive audiences at Northwestern University, Boston University, and UC Berkeley.
} 